\title{
Real-Time Pricing Decision Making for Retailer-Wholesaler in Smart Grid Based on Game Theory
}

\author{
Yeming Dai ${ }^{1,2}$ and Yan Gao ${ }^{1}$ \\ ${ }^{1}$ School of Management, University of Shanghai for Science and Technology, Shanghai 200093, China \\ ${ }^{2}$ College of Mathematics, Qingdao University, Qingdao 266071, China \\ Correspondence should be addressed to Yeming Dai; yemingdai@163.com
}

Received 8 May 2014; Accepted 2 June 2014; Published 24 June 2014

Academic Editor: Zidong Wang

Copyright (c) 2014 Y. Dai and Y. Gao. This is an open access article distributed under the Creative Commons Attribution License, which permits unrestricted use, distribution, and reproduction in any medium, provided the original work is properly cited.

\begin{abstract}
Real-time pricing DSM (demand side management) is widely used to dynamically change or shift the electricity consumption in the smart grid. In this paper, a game decision making scheme is proposed in the smart grid with DSM. The interaction between two retailers and their wholesaler is modeled as a two-stage game model. Considering the competition between two retailers, two different game models are developed in terms of the different action order between retailers and their wholesaler. Through analyzing the equilibrium revenues of the retailers for different situations we find that although the wholesaler expects to decentralize certain management powers to the retailers, it has retained the right to change the rules of the game and frequently reneged on the promises. More specifically, the law should ensure that any change of the revenue-sharing formula must go through certain legal procedures. Imposing legal restrictions on the wholesaler's discretionary policy suggests that the time-inconsistency problem is mitigated. Numerical simulation shows the effectiveness of proposed scheme.
\end{abstract}

\section{Introduction}

Today much more electricity grids have operated more than half a century and tend to be outdated even in some developed countries. Modernising electricity grids can increase the efficiency of electricity production and promote the use of grid assets and meanwhile makes the whole power network more reliable and secure so as to decrease carbon emission. The concept of smart grid has, especially, been arousing significant attention of much more researchers. The data communication networks play an important role during the development of smart grid. However, data communication network in smart grid is affected by many decisive factors such as different load and congestion level, changing customer demand, power generation, and different prices. These variable factors lead to different decision making problems. To solve these problems, demand side management (DSM) is a fine choice for residential customers to reduce the peak load and decrease the demand ability and costs in much more cases. DSM has been practiced since the early 1980s [1-3]. DSM is designed to affect the consumption of the customer electricity through implementing and monitoring practical activities. Usually, DSM can make users flatten the demand curve or shift the energy use to off-peak hours [4]. It is especially urgent to improve efficiency of the customers both in quantity and quality in power grid [5]. There is a significant scope for DSM to contribute to increasing the efficiency and use of system assets, for example, peak clipping, valley filling, load shifting, and flexible load shape [6]. Real-time pricing is one of the most effective DSM tools that can encourage users to consume electricity wisely. The reason is that the electricity is a very short-term commodity and economically nonstorable; that is, it has to be consumed the moment it is produced, where markets constantly experience short-term changes as capacity fluctuations from surplus to scarcity due to the hourly and daily fluctuation in demand. Considering the enhancement of the current power transmission and distribution systems with communication facilities and information technologies, real-time and adaptive pricing attract more attention. Adaptive pricing and peak load pricing have been practiced for many years [7-10]. In peak load pricing, the operating cycle is divided into several periods and instinct 
price is determined for each period. The prices are then announced ahead of time at the beginning of the operation cycle [9]. If real-time pricing is implemented, the price would become elastic on the demand side opposed to fixed price tariff. In real-time pricing, random events and the reaction of the customers to the previous prices will affect the price in the future [7]; then real-time pricing is conducive to realizing the linkage between demand side price and wholesale market clearing price as a kind of ideal dynamic electricity price mechanism. The market risk at proper points between power suppliers and users makes the retail price truly reflect realtime electricity costs change, really achieve paretooptimal efficiency of the market, and realize the optimal allocation of power resources and maximization of total social benefit.

The spreading technologies and services in smart grid imply that game theory and some other more up-to-date techniques [11-15] will naturally become a prominent tool in the design and analysis of real-time pricing in smart grids. In recent years, several efforts have been carried out to design intelligent systems for managing the energy consumption in real-time pricing. Mohsenian-Rad and Leon-Garcia utilize the smart grid and smart meters to provide an efficient power dispatching scheme for studying a single user's reaction [16]; Saad et al. use game theory to study the various decision making problems in the smart grid based on the DSM [17]. The Stackelberg game model is used to study the pricing problem of hierarchical decision problem in [18-20] and is adopted to study the real-time pricing based on the demand side in [21-24]. However, the proposed framework might not be suitable for all circumstances in practical electricity market. The reason is that the parallel structure in each layer and the order problem of the hierarchical structure are excluded from the object of study.

The Stackelberg game and Cournot game are unified into our model in our paper. The Stackelberg game is a game model in economics in which the leader firm moves first and then the follower firms move sequentially. Firms may engage in Stackelberg game if one has some sort of advantage enabling it to move first. More generally, the leader must have one commitment in power market. The Cournot game is an economic model used to describe an industry structure in which firms compete on quantity. The Stackelberg and Cournot models are similar in both competitions on quantity. However, a crucial advantage is given to the leader in Stackelberg game. The assumption of perfect information is also needed in the Stackelberg game; the follower must observe the strategy of the leader; otherwise the game reduces to Cournot game. Inspired by [25], we propose a real-time pricing method based on DSM using optimization technique and game theory. The novelty of this approach is threefold. Firstly, we jointly consider the optimization of consumers' revenues, integrating them into the retailers' problem. Secondly, in our model we not only consider the Stackelberg game between the retailers and wholesaler but also consider the Cournot game between the retailers to study the real-time pricing problem of bilevel decision. Last but not least, we consider the Stackelberg game between the retailers and wholesaler in different order of the hierarchical structure.
The remainder of this paper is organized as follows. In Section 2 we introduce the system model and the problem formulations, and we propose an efficient game model for electricity consumption scheduling between the wholesaler and retailers based on two different situations with elaborate mathematical analysis. In Section 3 the solution of model is proposed, and then a numerical analysis and simulation are done in Section 4. In Section 5, we evaluated the performance of the proposed model and a summary is provided.

\section{System Model and Problem Formulation}

We consider a smart grid with more than one retailer from which customers purchase electricity in electricity market liberalization. We aim to maximize the customers' utilities with minimum payment and increase the retailers' profit, so as to reduce peak to average load demand ratio through considering real-time varying prices. The retailers can compete or cooperate with each other in the electricity market to obtain the highest individual or combined revenue by varying price for the customers.

\subsection{Electricity Demand Models}

Utility Functions of Customers. Each customer is equipped with a smart meter in our model. The retailers set the real-time retail electricity prices and information for the customers via LAN. As far as customers are concerned, the energy scheduler in the smart meter can compute and distribute optimal energy consumption according to the prices for the upcoming time. Certainly customers always prefer to take lower prices to consume more electricity till reaching maximal consumption level if possible. Similar to [17], the utility function of each customer is taken as

$$
U(p, d)=X d-\frac{\alpha}{2} d^{2}-\xi p d
$$

where $X$ is varying parameter at different times of the day and among different customers, $d$ denotes the customer's electricity demand, $\alpha$ is a parameter that is pre-determined, $\xi$ indicates the price elasticity of electricity demand, and $p$ is the price provided by the retailer.

Since real-time pricing DSM is an effective tool to direct and affect the electricity consumption behavior of customers, each customer adjusts electricity consumption level to maximize utility according to real-time prices which are offered by the retailers. Each customer's electricity consumption can be calculated on the base of utility function. The electricity demand function of each customer $D(p)$ can be obtained by maximizing the following utility function:

$$
D(p)=\frac{X-\xi p}{\alpha} .
$$

Retailers' Electricity Demand Function. Assuming that there are $M$ wholesalers and $N$ electricity retailers in the electricity market, the retailers procure electricity from the wholesalers and provide the electricity for customers. Different retailers offered different price for customers they serve. The lower 
price attracts more customers and the customers can turn to other retailers in that area. So the electricity demand of retailer $i$ can be shown as follows:

$$
D_{i}(p)=D_{i}-\xi_{i} p_{i}+\sum_{n=1, n \neq i}^{N} v_{i, n} p_{n},
$$

where $p=\left(p_{1}, p_{2}, \ldots, p_{n}\right)$ denotes the price vector offered by the retailers, $D_{i}$ denotes varying parameter with different retailers and time, $\xi_{i}$ denotes the price elasticity of electricity demand of retailer $i, p_{i}$ denotes the price offered by retailer $i$, and $v_{i, n}\left(0 \leq v_{i, n} \leq 1\right)$ represents the proportion of electricity demand flowing from retailer $n$ to retailer $i$ for a given price from retailer $n$.

2.2. Revenue of Electricity Retailers and Wholesaler. Solving the equilibrium of game based on multiple wholesalers and multiple retailers will yield nonsmooth problems. It is a hard work for the traditional game algorithm and needs to use the corresponding nonsmooth optimization algorithm to solve them; in this paper we only consider the case that there are one wholesaler and two retailers in the electricity market for simplicity. The wholesaler wholesales electricity to retailers and chooses the percentages of retailers' revenue to be submitted to him, where the retailers make the decision on how much revenue to procure in their jurisdictions. The revenue function of retailer $i$ can be expressed as

$$
y_{i}(p)=D_{i}(p) p_{i}, \quad i=1,2 .
$$

The budget revenue function of wholesaler can be expressed as

$$
R_{w}=y_{1}(p) x_{1}+y_{2}(p) x_{2},
$$

where $x_{i}(i=1,2)$ denotes the share of revenue submitted to the wholesaler from the retailer $i$. The budget revenue function of retailer $i$ can be expressed as

$$
L_{i}=\left(1-x_{i}\right) y_{i}(p), \quad i=1,2,
$$

where the net income of the retailer $i$ after deducting the cost from budget revenue is, namely,

$$
R_{i}=\left(1-x_{i}\right) y_{i}-C_{i}\left(y_{i}\right), \quad i=1,2,
$$

where $C_{i}\left(y_{i}\right)$ denotes cost; assume marginal costs rise with the increase of income, specially; we set $C_{i}\left(y_{i}\right)=a_{i} y_{i}^{2}$. In general, $a_{1} \neq a_{2}$; we can regard $a_{i}$ as the parameter representing regional development level. The higher the level of development is, the smaller the $a_{i}$ is.

The wholesaler aims to minimize the income gap between retailers after ensuring its fundamental spending needs. So the wholesaler's preferences can be expressed with a logarithmic function defined on the retailer' budget revenue as follows:

$$
U=\ln \left(1-x_{1}\right) y_{1}+\ln \left(1-x_{2}\right) y_{2} .
$$

The retailers can be noncooperative or cooperative with each other; that is, each retailer maximizes its individual utility disregarding the benefit of the other retailer, or the retailers maximize the sum of their utility in the game.

\subsection{Game Model Formulation}

2.3.1. The Wholesaler Can Abide by the Commitment. The wholesaler and the two retailers play a two-stage game. The timing of this game is as follows.

Let the wholesaler move first. The retailers move and will have incentive to obtain more revenues.

The game proceeds as follows:

(1) Stage 1: the wholesaler announces $x_{1}$ and $x_{2}$;

(2) Stage 2: retailer 1 and retailer 2 choose $p_{1}$ and $p_{2}$ simultaneously after observing $x_{1}$ and $x_{2}$.

The above assumption says that the wholesaler plays a Stackelberg game with the retailers and the wholesaler moves first (as the leader). Under such regime, the retailers obtain their revenues through serving electricity customers after knowing the wholesaler's offer of $x_{i}$, while the wholesaler takes into account the retailers' reaction to $x_{i}$ and finds the optimal $x_{i}$. In terms of retailers, they play a Cournot game in which both players do not have the information about other player's move and maximize the sum of their utility.

Definition 1. The equilibrium is defined as follows.

(1) The wholesaler acts optimally given the retailers' reaction functions. (2) The retailer $i$ optimizes his revenue given the wholesaler's announced $x_{i}$ and retailer's revenue.

The wholesaler's aim is to solve the problem,

$$
\begin{array}{ll}
\max _{x_{1}, x_{2}} & U=\ln \left(1-x_{1}\right) y_{1}+\ln \left(1-x_{2}\right) y_{2} \\
\text { s.t. } & x_{1} y_{1}+x_{2} y_{2} \geq E
\end{array}
$$

where $E$ is spending needs which is assumed as small enough so that $x_{i} \leq 1, i=1,2$, while the aim of the retailers is to maximize the net income after deducting the cost from budget revenue; namely,

$$
\max _{y_{i}} R_{i}=\left(1-x_{i}\right) y_{i}-C_{i}\left(y_{i}\right), \quad i=1,2 .
$$

2.3.2. The Wholesaler Cannot Abide by the Commitment. The wholesaler and the two retailers play a two-stage game, but the order of game is changed. The wholesaler can modify arbitrarily the payout rate despite the commitment in advance; the action sequence of this game is that retailers move firstly.

(1) Stage 1: retailer 1 and retailer 2 choose $p_{1}$ and $p_{2}$;

(2) Stage 2: after observing $p_{1}$ and $p_{2}$, the wholesaler chooses $x_{1}$ and $x_{2}$.

The above assumption states that the wholesaler plays a Stackelberg game with the retailers and the retailers move first. The retailers are the leaders and the wholesaler is the follower in the game. This assumption embodies the true feature of current Chinese economic system. The wholesaler does not precommit to a fixed revenue sharing method and the retailers often take this reality into account when determining their revenues; in this ease the two retailers are still noncooperative and play a Cournot game between them as they move simultaneously. 
Definition 2. The equilibrium is defined as follows.

(1) The wholesaler responds optimally given each retailer's collected revenues.

(2) The retailer $i$ optimizes its collected revenue given the wholesaler's reaction function and retailer $j$ 's choice of revenue collection $(i \neq j, i, j=1,2)$.

\section{Solution of the Game Model}

3.1. The Wholesaler Can Abide by the Commitment. To find the equilibrium of the game when the wholesaler can abide by the commitment, we use backward induction. In other words, we first solve for the retailers' reaction function. Believing that the wholesaler will commit constant $x_{1}$, retailer 1 chooses $p_{1}$ to maximize

$$
R_{1}=\left(1-x_{1}\right) y_{1}-a_{1} y_{1}^{2},
$$

where $x_{1}$ is fixed. This yields the optimal revenue $y_{1}$ under the commitment regime satisfying $d R_{1} / d y_{1}=0$; the solution is

$$
y_{1}^{*}=\frac{1-x_{1}}{2 a_{1}}
$$

For retailer 2,

$$
R_{2}=\left(1-x_{2}\right) y_{2}-a_{2} y_{2}^{2},
$$

where $x_{1}$ is fixed. This leads to the optimal revenue $y_{2}$ under the commitment regime satisfying $d R_{1} / d y_{1}=0$; its optimal revenue is

$$
y_{2}^{*}=\frac{1-x_{2}}{2 a_{2}}
$$

By introducing (3) and (4) to (12) and (14), respectively, we have

$$
\begin{aligned}
& \left(D_{1}-\xi_{1} p_{1}+v_{1,2} p_{2}\right) p_{1}=\frac{1-x_{1}}{2 a_{1}} \\
& \left(D_{2}-\xi_{2} p_{2}+v_{2,1} p_{1}\right) p_{2}=\frac{1-x_{2}}{2 a_{2}} .
\end{aligned}
$$

By (15), we obtain

$$
\begin{aligned}
& p_{1}^{*}=\frac{\left(\left(\left(1-x_{2}\right) / 2 a_{2} p_{2}^{*}\right)+\xi_{2} p_{2}^{*}-D_{2}\right)}{v_{2,1}}, \\
& p_{2}^{*}=\frac{\left(\left(\left(1-x_{1}\right) / 2 a_{1} p_{1}^{*}\right)+\xi_{1} p_{1}^{*}-D_{1}\right)}{v_{1,2}} .
\end{aligned}
$$

Now return to the wholesaler's problem. The wholesaler chooses $x_{1}$ and $x_{2}$ to aim for

$$
\begin{array}{ll}
\max _{x_{1}, x_{2}} & U=\ln \left(1-x_{1}\right) y_{1}^{*}+\ln \left(1-x_{2}\right) y_{2}^{*}, \\
\text { s.t. } & x_{1} y_{1}^{*}+x_{2} y_{2}^{*} \geq E,
\end{array}
$$

where $y_{1}^{*}$ and $y_{2}^{*}$ are given by (12) and (14). Substituting (12) and (14) into (17), we can construct the Lagrange function

$$
\begin{aligned}
L= & \frac{\ln \left(1-x_{1}\right)^{2}}{2 a_{1}}+\frac{\ln \left(1-x_{2}\right)^{2}}{2 a_{2}} \\
& +\lambda\left[\frac{x_{1}\left(1-x_{1}\right)}{2 a_{1}}+\frac{x_{2}\left(1-x_{2}\right)}{2 a_{2}}-E\right] .
\end{aligned}
$$

The first-order optimality conditions are

$$
\begin{gathered}
\frac{\partial L}{\partial x_{1}}=-\frac{2}{1-x_{1}}+\lambda \frac{1-2 x_{1}}{2 a_{1}}=0 ; \\
\frac{\partial L}{\partial x_{2}}=-\frac{2}{1-x_{2}}+\lambda \frac{1-2 x_{2}}{2 a_{1}}=0 ; \\
\frac{\partial L}{\partial \lambda}=\frac{x_{1}\left(1-x_{1}\right)}{2 a_{1}}+\frac{x_{2}\left(1-x_{2}\right)}{2 a_{2}}-E=0 .
\end{gathered}
$$

Eliminating $\lambda$ from (19) gives $\left(1 / a_{1}\right)\left(1-x_{1}\right)\left(1-2 x_{1}\right)=$ $\left(1 / a_{2}\right)\left(1-x_{2}\right)\left(1-2 x_{2}\right)$, and we also can see $x_{1}<1 / 2, x_{2}<1 / 2$ from (19); therefore, we have

$$
y_{i}^{c *}>\frac{1}{4 a_{i}} \quad(i=1,2) .
$$

On the other hand, the budget constraint can be rewritten as

$$
\frac{x_{1}\left(1-x_{1}\right)}{2 a_{1}}+\frac{x_{2}\left(1-x_{2}\right)}{2 a_{2}}=E \text {. }
$$

Equation (21) defines the optimal point $x_{i}^{*}(i=1,2)$ under commitment. But solving the two equations yields a third-order polynomial equation. We have the following proposition through the previous derivation.

Proposition 3. The equilibrium of the game when the wholesaler can abide by the commitment satisfies the following conditions:

$$
\begin{gathered}
p_{2}^{*}=\frac{\left(\left(\left(1-x_{1}^{*}\right) / 2 a_{1} p_{1}^{*}\right)+\xi_{1} p_{1}^{*}-D_{1}\right)}{v_{1,2}}, \\
p_{1}^{*}=\frac{\left(\left(\left(1-x_{2}^{*}\right) / 2 a_{2} p_{2}^{*}\right)+\xi_{2} p_{2}^{*}-D_{2}\right)}{v_{2,1}}, \\
\frac{1}{a_{1}}\left(1-x_{1}^{*}\right)\left(1-2 x_{1}^{*}\right)=\frac{1}{a_{2}}\left(1-x_{2}^{*}\right)\left(1-2 x_{2}^{*}\right), \\
\frac{x_{1}^{*}\left(1-x_{1}^{*}\right)}{2 a_{1}}+\frac{x_{2}^{*}\left(1-x_{2}^{*}\right)}{2 a_{2}}=E .
\end{gathered}
$$

3.2. The Wholesaler Cannot Abide by the Commitment. To find the equilibrium, we use backward induction. The wholesaler's aim is

$$
\begin{array}{ll}
\max _{x_{1}, x_{2}} & U=\ln \left(1-x_{1}\right) y_{1}+\ln \left(1-x_{2}\right) y_{2} \\
\text { s.t. } & x_{1} y_{1}+x_{2} y_{2} \geq E .
\end{array}
$$


The first-order condition of problem (23) is equivalent to the following equation:

$$
\left(1-x_{1}\right) y_{1}=\left(1-x_{2}\right) y_{2}
$$

Namely, the wholesaler will equalize the budget revenues between the two retailers, given the optimal levels of $x_{1}$ and $x_{2}$ as functions of $y_{1}, y_{2}$, and $E$; the reaction function of the wholesaler is

$$
\begin{aligned}
& x_{1}\left(y_{1}, y_{2}\right)=\frac{1}{2}-\frac{y_{2}-E}{2 y_{1}}, \\
& x_{2}\left(y_{1}, y_{2}\right)=\frac{1}{2}-\frac{y_{1}-E}{2 y_{2}} .
\end{aligned}
$$

The above reaction function means payout rate of a retailer increases with the rising of its relative income and decreases with the falling of the other retailers' falling of the other retailer's relative income. Because the retailers know the reaction function of the wholesaler, in the first stage of game, the problems of the retailers are to maximize their individual utility

$$
R_{i}=\left(1-x_{i}\left(y_{1}, y_{2}\right)\right) y_{i}-a_{i} y_{i}^{2}, \quad i=1,2
$$

The first-order condition determines that the optimal $y_{i}$ is

$$
\frac{\partial R_{i}}{\partial y_{i}}=\frac{1}{2}+\frac{\partial y_{j}}{\partial y_{i}}-2 a_{i} y_{i}=0, \quad i \neq j, i, j=1,2
$$

Through the Cournot game assumption $\partial y_{i} / \partial y_{j}=0, i \neq j$, $i, j=1,2$, we can solve the Nash equilibrium as follows:

$$
y_{1}^{\mathrm{nc} *}=\frac{1}{4 a_{1}}, \quad y_{2}^{\mathrm{nc} *}=\frac{1}{4 a_{2}} \text {. }
$$

The wholesaler substitutes (28) into (25) and obtains equilibrium

$$
\begin{gathered}
x_{1}^{*}=\frac{1}{2}-\frac{a_{1}}{2 a_{2}}+2 a_{1} E, \quad x_{2}^{*}=\frac{1}{2}-\frac{a_{2}}{2 a_{1}}+2 a_{2} E, \\
\left(D_{1}-\xi_{1} p_{1}+v_{1,2} p_{2}\right) p_{1}=\frac{1}{4 a_{1}} \\
\left(D_{2}-\xi_{2} p_{2}+v_{2,1} p_{1}\right) p_{2}=\frac{1}{4 a_{2}} .
\end{gathered}
$$

By solving the two equations, we obtain the equilibrium price

$$
\begin{aligned}
& p_{1}^{*}=\frac{\left(\left(1 / 4 a_{2} p_{2}^{*}\right)+\xi_{2} p_{2}^{*}-D_{2}\right)}{v_{2,1}}, \\
& p_{2}^{*}=\frac{\left(\left(1 / 4 a_{1} p_{1}^{*}\right)+\xi_{1} p_{1}^{*}-D_{1}\right)}{v_{1,2}} .
\end{aligned}
$$

Therefore, we have the following proposition through the previous derivation.
Proposition 4. The equilibrium of the game when the wholesaler cannot abide by the commitment satisfies the following conditions:

$$
\begin{gathered}
p_{1}^{*}=\frac{\left(\left(1 / 4 a_{2} p_{2}^{*}\right)+\xi_{2} p_{2}^{*}-D_{2}\right)}{v_{2,1}}, \\
p_{2}^{*}=\frac{\left(\left(1 / 4 a_{1} p_{1}^{*}\right)+\xi_{1} p_{1}^{*}-D_{1}\right)}{v_{1,2}}, \\
x_{1}^{*}=\frac{1}{2}-\frac{a_{1}}{2 a_{2}}+2 a_{1} E \\
x_{2}^{*}=\frac{1}{2}-\frac{a_{2}}{2 a_{1}}+2 a_{2} E .
\end{gathered}
$$

\section{Model Analysis and Simulation}

We observe the change trend when we assume that $a_{1}=0.04$, $a_{2}=0.01$, and $E=20, v_{1,2}=v_{2,1}=0.3, \xi_{1}=\xi_{2}=0.5$. We vary the number of $D_{1}$ when $D_{2}$ changes from 0 to 5 to study how they affect the equilibrium price.

Firstly, we simulate the situation that the wholesaler can abide by the commitment. From (22) we have

$$
\begin{array}{r}
p_{2}^{*}=\frac{\left(\left(\left(1-x_{1}^{*}\right) / 0.056 p_{1}^{*}\right)+0.5 p_{1}^{*}-D_{1}\right)}{0.3}, \\
p_{1}^{*}=\frac{\left(\left(\left(1-x_{2}^{*}\right) / 0.014 p_{2}^{*}\right)+0.5 p_{2}^{*}-D_{2}\right)}{0.3}, \\
x_{1}^{*}=0.2, \quad x_{2}^{*}=0.4 .
\end{array}
$$

In Figure 1, when $D_{1}$ keeps constant and $D_{2}$ grows to the low regional development level the increase of electricity demand results in short supply which causes prices to rise for retailer 2. But the change trends of two equilibrium price vary greatly. Retailer 1 maintains price stability in electricity demand stable circumstances, which can be explained by the low level of development. Retailer 1 can only expand electricity price instead of expanding production.

Next we simulate the situation that the wholesaler cannot abide by the commitment. From (31) we have

$$
\begin{gathered}
p_{1}^{*}=\frac{\left(\left(1 / 0.028 p_{2}^{*}\right)+0.5 p_{2}^{*}-D_{2}\right)}{0.3}, \\
p_{2}^{*}=\frac{\left(\left(1 / 0.112 p_{1}^{*}\right)+0.5 p_{1}^{*}-D_{1}\right)}{0.3}, \\
x_{1}^{*}=0.1 \\
x_{2}^{*}=0.775
\end{gathered}
$$

In Figure 2, the change trends of equilibrium price stay similar to Figure 1; $p_{1}^{*}$ increases much faster than it does in Figure 1 which shows the effect of actions in a different order.

In addition to the above situation, we also can verify the key differences of the retailers' revenue between the two cases through comparing the two kinds of equilibrium. From the above section it can be seen that each retailer ignores 


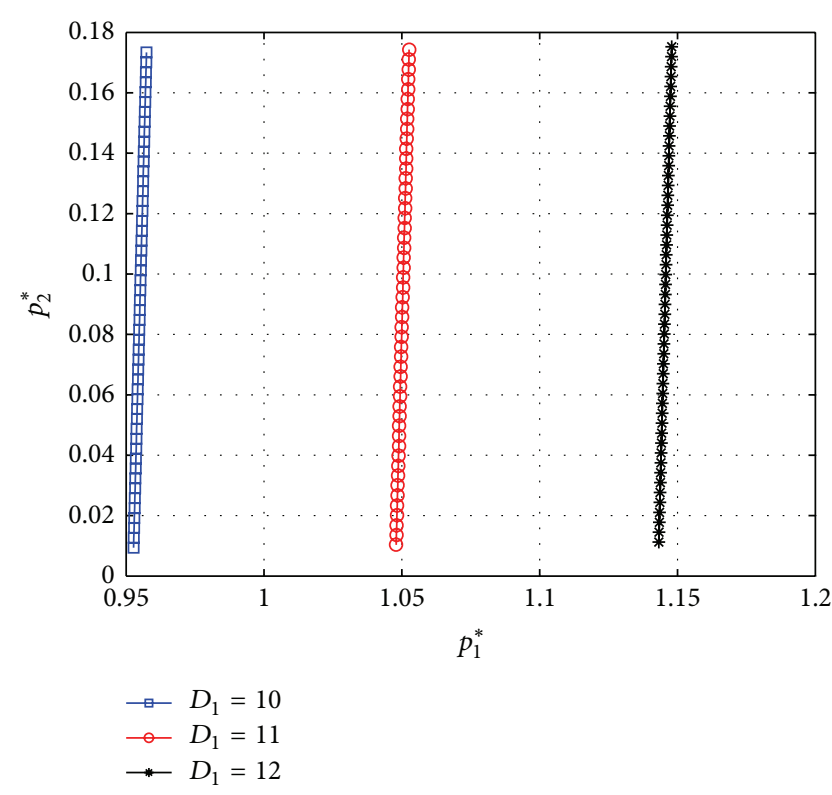

FIgURE 1: Equilibrium price chart affected by $D_{1}, D_{2}$ when wholesaler abides by the commitment.

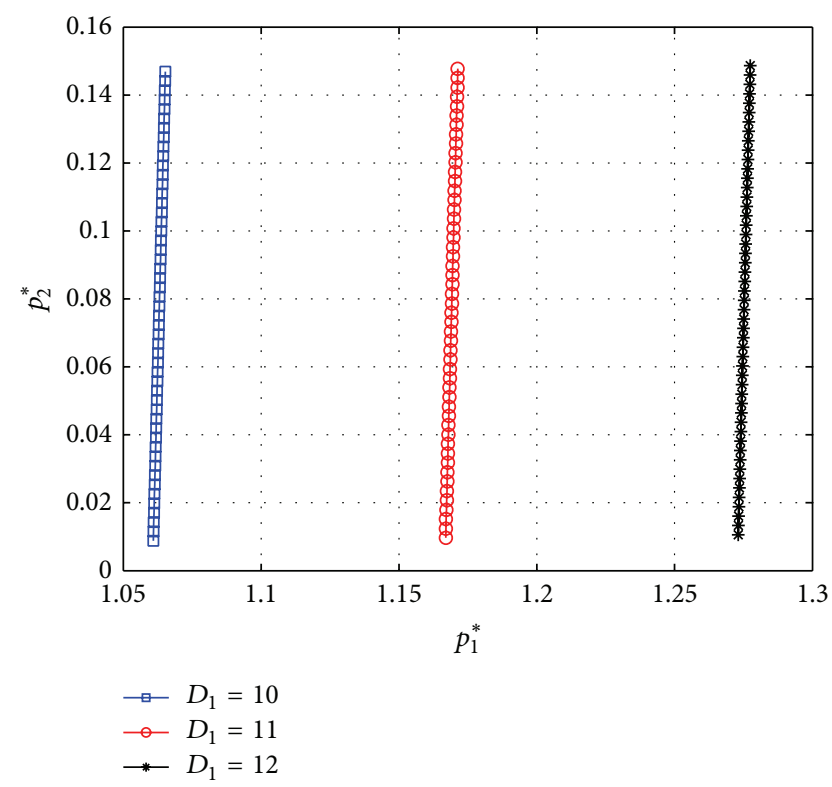

FIGURE 2: Equilibrium price change trend chart affected by $D_{1}, D_{2}$ when the wholesaler cannot abide by the commitment.

the externality problem (one retailer's revenue collection can affect the other retailers' share of revenue submitted to the wholesaler). Moreover, a revenue distortion is involved in the no-commitment case as retailers are tempted to reduce their efforts in order to avoid high rate. However, the externality of a retailer's revenue disappears under the commitment regime since the wholesaler precommits to fixed rates, which increases the retailers' revenue, but the predetermined rates can create distortions on the retailer's revenue. So we should consider two factors when comparing the two cases.
On one hand, the absence of the externality can contribute to higher revenue in the commitment case compared with the no-commitment case; on the other hand, the two cases involve a distortion that reduces retailers' revenue which yields higher revenue levels in the commitment case than the no-commitment case. From (20) and (28) we know $y_{1}^{\mathrm{nc} *}<y_{1}^{\mathrm{c} *}, y_{2}^{\mathrm{nc} *}<y_{2}^{\mathrm{c} *}$ at different equilibrium price. The commitment case provides a way to partially overcome the retailers' incentive problem in the no-commitment case. Firstly, the institution is not adequate for restricting the wholesaler from reneging on preannounced declaring; that is, there is no legal restriction on the wholesaler's contract revision. Secondly, the wholesaler still does not want to commit after knowing that the commitment case can yield higher level of revenue than the no-commitment case. The problem is that the wholesaler's policy is time-inconsistent. Suppose the wholesaler preannounces the optimal rates, but the wholesaler wants to change the preannounced rates after having observed the realized revenues; then the optimal policy is time-inconsistent. In view of this, the promise made by the wholesaler becomes incredible to the retailers.

\section{Conclusion}

In this paper, we propose a novel game-theoretical decision making scheme for electricity retailers and wholesaler in the smart grid with DSM. The interaction between two retailers and their wholesaler has been modeled as a twostage dynamic game, in which the competition between two retailers is considered. Two different game models are constructed in terms of the different action order between retailers and their wholesaler. Backward induction is used to determine the SPE of the game.

Through analyzing the equilibrium revenues of the retailers in different situations we find that the wholesaler wants to decentralize certain management powers to the retailers. As he has retained the right to change the rules of the game, he frequently reneged on the promises when he thought "necessary." Imposing legal restrictions on the wholesaler's discretionary policy suggests that the time-inconsistency problem is mitigated. Numerical simulation shows the effectiveness of proposed conclusion and effect of parameters on the equilibrium price.

More wholesalers and retailers will be researched in the direction as a possible future extension for the electricity market. The main results of this paper will be extended to other complex systems [26-30].

\section{Conflict of Interests}

The authors declare that there is no conflict of interests regarding the publication of this paper.

\section{Acknowledgments}

This work is supported by the National Natural Science Foundation of China (nos. 11171221 and 71171120), Research Fund for the Doctoral Program of Higher Education of 
China (no. 20123120110004), Shanghai Leading Academic Discipline (no. XTKX2012), Program of Natural Science of Shanghai (no. 14ZR1429200), and the SUR on IOT-based Customer/Grid Interaction in Smart Grid.

\section{References}

[1] C. W. Gellings, "The concept of demand side management for electric utilities," Proceedings of the IEEE, vol. 73, no. 10, pp. 1468-1470, 1985.

[2] M. Fahrioglu and F. L. Alvarado, "Designing incentive compatible contracts for effective demand management," IEEE Transactions on Power Systems, vol. 15, no. 4, pp. 1255-1260, 2000.

[3] B. Ramanathan and V. Vittal, "A framework for evaluation of advanced direct load control with minimum disruption," IEEE Transactions on Power Systems, vol. 23, no. 4, pp. 1681-1688, 2008.

[4] T. Logenthiran, D. Srinivasan, and T. Z. Shun, "Demand side management in smart grid using heuristic optimization," IEEE Transactions on Smart Grid, vol. 3, no. 3, pp. 1244-1252, 2012.

[5] IEEE Guide for Smart Grid Interoperability of Energy Technology and Information Technology Operation with the Electric Power System (eps), End-Use Applications, and Loads, IEEE Standard 2030-2011, 2011.

[6] Y. M. Dai, H. W. Gao, M. Xu et al., "Main diagonal dominant principle and algorithm of equilibrium in joint mixed strategies for bimatrix games," Systems Engineering-Theory \& Practice, vol. 33, no. 6, pp. 1523-1529, 2013.

[7] P. B. Luh, Y. C. Ho, and R. Muralidharan, "Load adaptive pricing: an emerging tool for electric utilities," IEEE Transactions on Automatic Control, vol. 27, no. 2, pp. 320-329, 1982.

[8] Y. Tang, H. Song, F. Hu, and Y. Zou, "Investigation on TOU pricing principles," in Proceedings of the IEEE/PES Transmission and Distribution Conference and Exhibition: Asia and Pacific, pp. 1-9, Dalian, China, August 2005.

[9] M. A. Crew, C. S. Fernando, and P. R. Kleindorfer, "The theory of peak-load pricing: a survey," Journal of Regulatory Economics, vol. 8, no. 3, pp. 215-248, 1995.

[10] S. Zeng, J. Li, and Y. Ren, "Research of time-of-use electricity pricing models in China: a survey," in Proceedings of the IEEE International Conference on Industrial Engineering and Engineering Management (IEEM '08), pp. 2191-2195, Singapore, December 2008.

[11] J. Hu, Z. Wang, B. Shen, and H. Gao, "Quantised recursive filtering for a class of nonlinear systems with multiplicative noises and missing measurements," International Journal of Control, vol. 86, no. 4, pp. 650-663, 2013.

[12] X. He, Z. Wang, X. Wang, and D. H. Zhou, "Networked strong tracking filtering with multiple packet dropouts: algorithms and applications," IEEE Transactions on Industrial Electronics, vol. 61, no. 3, pp. 1454-1463, 2014.

[13] Z. Wang, D. Ding, H. Dong, and H. Shu, " $H_{\infty}$ consensus control for multi-agent systems with missing measurements: the finitehorizon case," Systems and Control Letters, vol. 62, no. 10, pp. 827-836, 2013.

[14] Z. Wang, H. Dong, B. Shen, and H. Gao, "Finite-horizon $H_{\infty}$ filtering with missing measurements and quantization effects," IEEE Transactions on Automatic Control, vol. 58, no. 7, pp. 1707$1718,2013$.
[15] H. Dong, Z. Wang, and H. Gao, "Fault detection for markovian jump systems with sensor saturations and randomly varying nonlinearities," IEEE Transactions on Circuits and Systems I: Regular Papers, vol. 59, no. 10, pp. 2354-2362, 2012.

[16] A. Mohsenian-Rad and A. Leon-Garcia, "Optimal residential load control with price prediction in real-time electricity pricing environments," IEEE Transactions on Smart Grid, vol. 1, no. 2, pp. 120-133, 2010.

[17] W. Saad, Z. Han, H. V. Poor, and T. Başar, "Game-theoretic methods for the smart grid: an overview of microgrid systems, demand-side management, and smart grid communications," IEEE Signal Processing Magazine, vol. 29, no. 5, pp. 86-105, 2012.

[18] E. Pettersen, A. B. Philpott, and S. W. Wallace, "An electricity market game between consumers, retailers and network operators," Decision Support Systems, vol. 40, no. 3-4, pp. 427-438, 2005.

[19] V. Radonjić and V. Aćimović-Raspopović, "Responsive pricing modeled with Stackelberg game for next-generation networks," Annals of Telecommunications, vol. 65, no. 7-8, pp. 461-476, 2010.

[20] M. Labbé and A. Violin, "Bilevel programming and price setting problems," 4OR, vol. 11, no. 1, pp. 1-30, 2013.

[21] S. Bu, F. R. Yu, and P. X. Liu, "A game-theoretical decisionmaking scheme for electricity retailers in the smart grid with demand-side management," in Proceedings of the IEEE International Conference on Smart Grid Communications (SmartGridComm 11), pp. 387-391, Brussels, Belgium, October 2011.

[22] C. Chen, S. Kishore, and L. V. Snyder, "An innovative RTPbased residential power scheduling scheme for smart grids," in Proceedings of the IEEE International Conference on Acoustics, Speech and Signal Processing (ICASSP '11), pp. 5956-5959, Prague, Czech Republic, May 2011.

[23] J. Chen, B. Yang, and X. Guan, "Optimal demand response scheduling with Stackelberg game approach under load uncertainty for smart grid," in Proceedings of the IEEE 3rd International Conference on Smart Grid Communications (SmartGridComm '12), pp. 546-551, Tainan, Taiwan, November 2012.

[24] K. M. Tsui and S. C. Chan, "Demand response optimization for smart home scheduling under real-time pricing," IEEE Transactions on Smart Grid, vol. 3, no. 4, pp. 1812-1821, 2012.

[25] J. Ma, "Modelling central-local fiscal relations in China," China Economic Review, vol. 6, no. 1, pp. 105-136, 1995.

[26] H. Dong, Z. Wang, and H. Gao, "Distributed $H_{\infty}$ filtering for a class of markovian jump nonlinear time-delay systems over lossy sensor networks," IEEE Transactions on Industrial Electronics, vol. 60, no. 10, pp. 4665-4672, 2013.

[27] B. Shen, Z. Wang, D. Ding, and H. Shu, " $H_{\infty}$ state estimation for complex networks with uncertain inner coupling and incomplete measurements," IEEE Transactions on Neural Networks and Learning Systems, vol. 24, no. 12, pp. 2027-2037, 2013.

[28] L. Qin, X. He, and D. H. Zhou, "A survey of fault diagnosis for swarm systems," Systems Science and Control Engineering, vol. 2, no. 1, pp. 13-23, 2014.

[29] Q. Liu, Z. Wang, X. He, and D. H. Zhou, "A survey of eventbased strategies on control and estimation," Systems Science and Control Engineering, vol. 2, no. 1, pp. 90-97, 2014.

[30] B. Shen, "A survey on the applications of the Krein-space theory in signal estimation," Systems Science and Control Engineering, vol. 2, no. 1, pp. 143-149, 2014. 


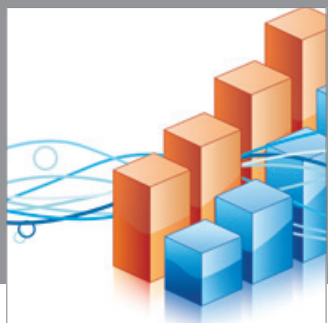

Advances in

Operations Research

mansans

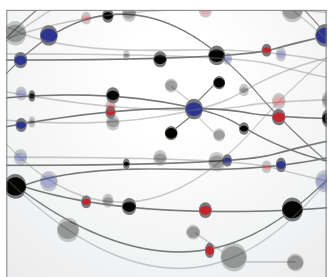

The Scientific World Journal
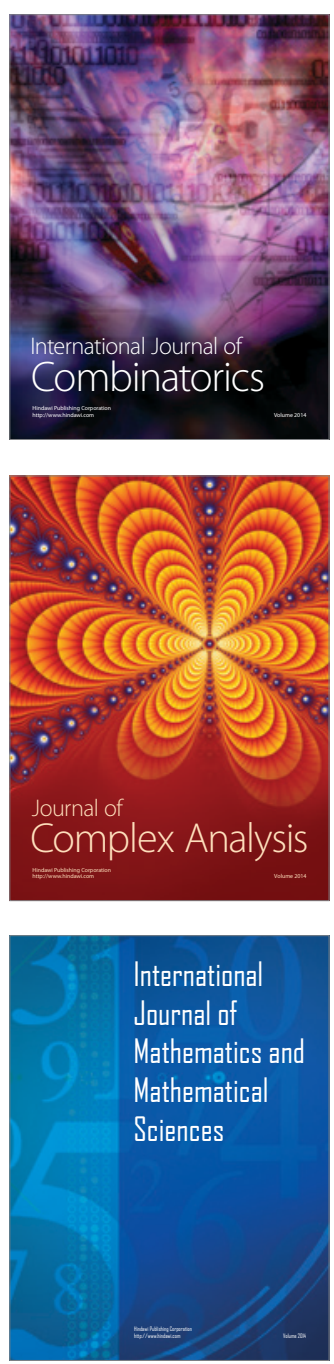
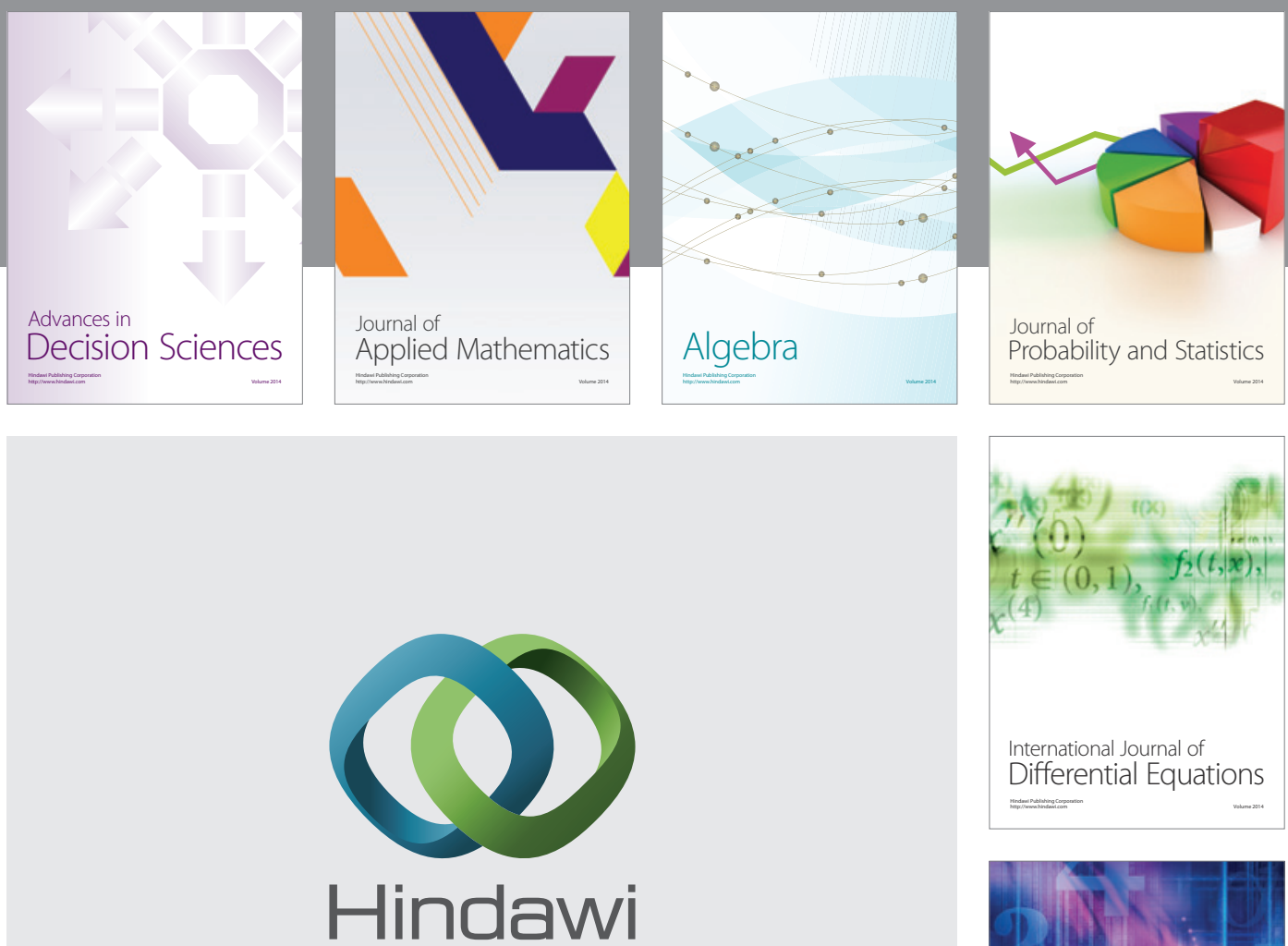

Submit your manuscripts at http://www.hindawi.com
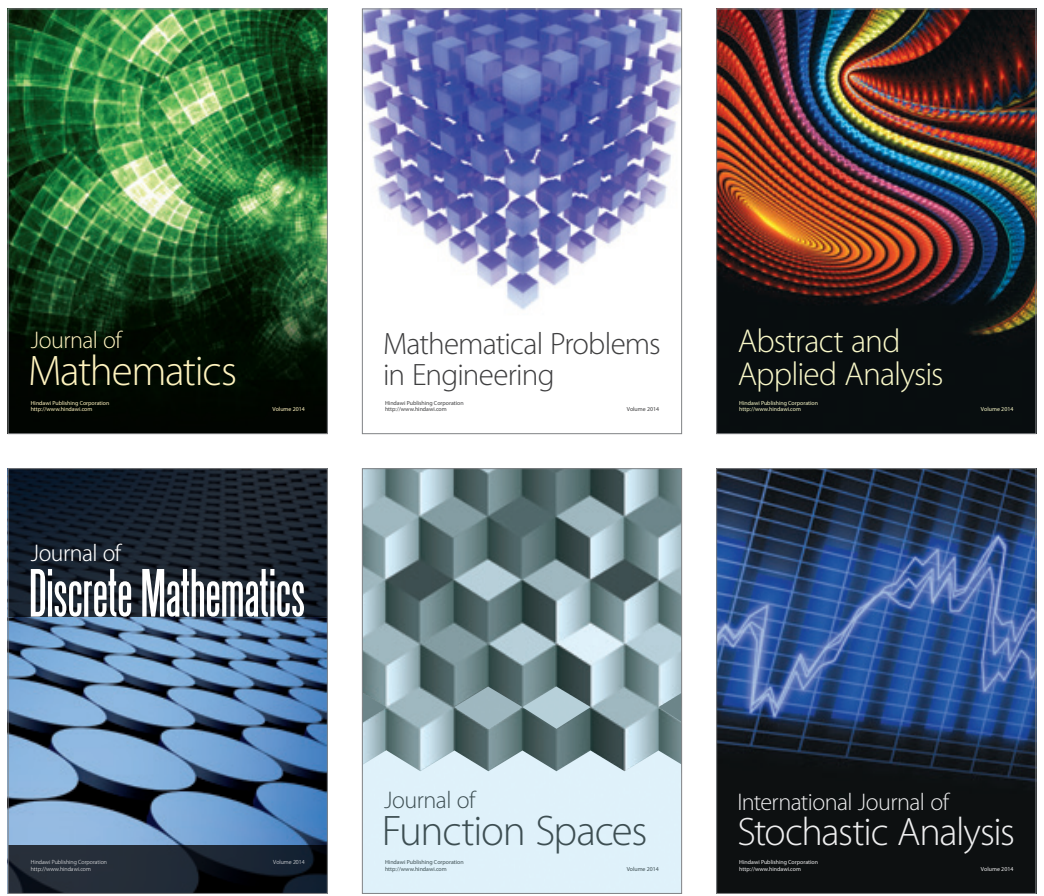

Journal of

Function Spaces

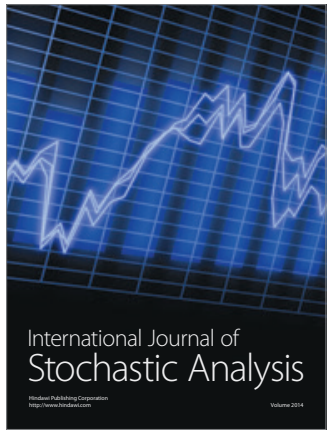

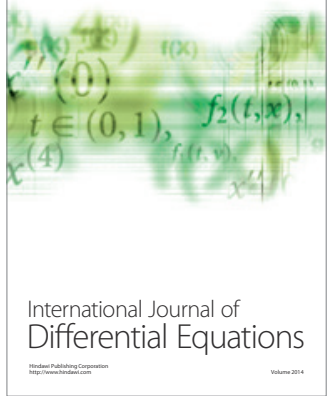
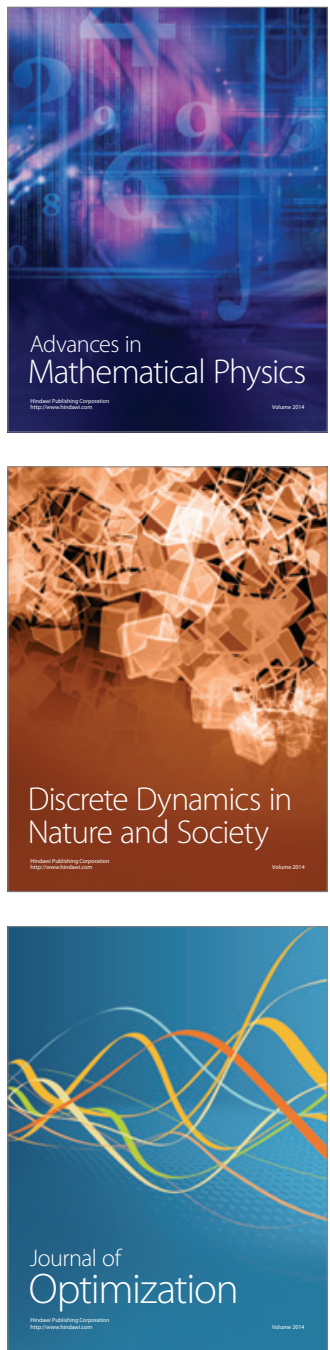